\title{
DIFFUSE REFLECTANCE INFRARED FOURIER TRANSFORM SPECTROSCOPY (DRIFTS) APPLIED TO THE CHEMICAL CHARACTERIZATION OF DIESEL SOOT
}

\author{
TAPIA A. ${ }^{1, *}$ \\ SALGADO $S^{1}$ \\ SÁNCHEZ-VALDEPEÑAS J. ${ }^{2}$ \\ MARTÍN P. ${ }^{1}$ \\ RODRÍGUEZ J. ${ }^{2}$ \\ CABAÑAS B. ${ }^{1}$
}

\author{
${ }^{1}$ Physical Chemistry Department, University of Castilla-La Mancha \\ Avda. Camilo José Cela s/n \\ 13071 Ciudad Real, Spain \\ ${ }^{2}$ Grupo de Combustibles y Motores \\ Escuela Técnica Superior de Ingenieros Industriales \\ University of Castilla-La Mancha \\ Avda. Camilo José Cela s/n, 13071 Ciudad Real, Spain
}

Received: $27 / 05 / 2015$

Accepted: 11/04/2016

Available online: 19/05/2016

*to whom all correspondence should be addressed: e-mail: araceli.tapia@uclm.es

\section{ABSTRACT}

In this work, diesel soot has been characterized chemically using a diffuse reflectance infrared Fourier transform spectroscopy (DRIFTS) technique. Diesel soot samples were generated under combustion conditions reproducing the typical urban operating mode of a diesel engine. Initial experiments performed to ensure the repeatability of the DRIFTS analysis and the sample preparation method showed that the standard deviations were always lower than $20 \%$ for the DRIFTS analysis itself, and lower than $25 \%$ when sample preparation was included. This is of special interest as regards application of the DRIFTS technique for quantitative analysis. The functional groups on the soot surface were identified on the basis of the infrared bands observed in the spectra at room temperature, indicating that the diesel soot analyzed comprises a mixture of aromatic hydrocarbons, carboxylic compounds, hydroxyl species, ether groups, and methylene and methyl groups. Analyses were also carried out at different temperatures in the interval of $298-858 \mathrm{~K}$ in order to analyze the thermal stability of the functional groups, with carbonyl groups, lactones and ethers appearing to be the most thermally stable compounds.

Keywords: DRIFTS, chemical characterization, Diesel, soot, engine

\section{Introduction}

Incomplete combustion of fossil fuels in diesel engines releases particulate matter (PM) of different diameters into the environment. These particles are considered to be a pollutant due to the presence of polycyclic aromatic hydrocarbons (PAHs), which have been implicated in chemical and photophysical processes in the atmosphere and are thought to be the primary cause of several diseases, adsorbed onto a carbonaceus material (Vieria de Souza and Machado Corrêa, 2015). Cancer and cardiopulmonary diseases, for example, are known to be related to the redox activity of PM. The dithiothreitol (DTT) assay provides a measure of the ability of PM to catalyse electron transfer between DTT and oxygen, and a high degree of correlation has been found between the redox activity of particulate emissions and physical and chemical characteristics of PM emitted by an engine running on diesel (Geller et al., 2006). Diesel exhaust particles (DEP) are also known to be involved in atmospheric processes as a result of the absorption of light by the black carbon and the organic matter present in it, thus affecting the radiation balance in the atmosphere (Guo et al., 2014; Schnaiter et al., 2003). As regards chemical processes, diesel

Tapia A., Salgado S., Sánchez-Valdepeñas J., Martín P., Rodríguez J. and Cabañas B. (2016), Diffuse Reflectance Infrared Fourier Transform Spectroscopy (DRIFTS) applied to the chemical characterization of diesel soot, Global NEST Journal, 18(3), 453-462. 
soot particles in urban and rural environments play an important role in the formation of SOA (secondary organic aerosol) under certain photochemical conditions, thereby affecting the chemical composition of the atmosphere (Lee et al., 2004).

Diesel engine emissions have gained considerable attention due to their health risks and environmental concerns, especially particulate matter and $\mathrm{NO}_{x}$ (Górski et al., 2013). As such, after-treatment devices and in-engine techniques such as diesel particulate filters (DPFs) and exhaust gas recirculation (EGR), have been implemented in diesel engines in recent years to decrease particulate matter and $\mathrm{NO}_{x}$ emissions (Lapuerta et al., 2012; Beatrice et al., 2012). As a result, it is of interest to characterize the soot collected from a DPF and to assess the impact of the type of soot generated on the behaviour and regeneration of a DPF (Zouaoui et al., 2014). Some studies in this regard have focused on evaluating the PM generated from conventional and alternative fuels in terms of their chemistry and morphology (Salamanca et al., 2012). It is also of particular interest to investigate the ability of soot to be oxidised by exhaust gases such as $\mathrm{NO}_{2}$ (Tighe et al., 2012) in different parts of the after-treatment assembly of the diesel engine in light of the morphological features of soot particles in relation to the temperature (Liati et al., 2013).

Several techniques, such as titration with a probe gas using a Knudsen reactor (Tapia et al., 2015), Raman spectroscopy (Sadezky et al., 2005), X-ray scattering and absorption spectroscopy (Braun et al., 2005), transmission electron microscopy (Wentzel et al., 2003; Yehliu et al., 2012) and diffuse reflectance infrared Fourier transform spectroscopy (Steiner et al., 2013), have recently been used to characterize the structure and composition of diesel soot. IR spectroscopy provides important information about the identity of molecular functional groups on the soot surface as a result of the characteristic vibrational frequencies of a functional group after absorbing infrared radiation (Jäger et al., 2007; Russo et al., 2012). Moreover, soot structure can be analyzed in relation to the spectral shift of the infrared band positions due to the chemical environment (Pino et al., 2008). The DRIFTS technique is based on the infrared light reflected in all directions after incidence on the sample surface and collected by use of an ellipsoid or paraboloid mirror onto the detector. As such, this technique can be extremely useful for non-transparent materials such as soot and/or for in situ measurements at elevated temperatures. For example, Liu et al. (2010) investigated the structural changes in soot during heterogeneous reaction with $\mathrm{O}_{3}$ at room temperature using an in situ DRIFTS technique. Similar experiments were carried out by Muchenhuber and Grothe (2007), who used DRIFTS to investigate the products of the reaction of soot with $\mathrm{NO}_{2}$ at different temperatures. Improved sensitivity and accuracy can be achieved by using attenuated total reflectance-Fourier transform infrared spectroscopy (ATR-FTIR), a technique derived from FTIR that has been used to quantify the functional groups of organic and inorganic compounds present in environmental aerosol particulate samples (Coury and Dillner, 2008).

The aim of this work was to apply the DRIFTS technique for the chemical characterization of samples of diesel soot obtained under a fixed engine condition.

\section{Methods}

Soot obtained from diesel fuel was analyzed using the DRIFTS technique in order to investigate the composition thereof and the functional groups present on the particles' surface. A Nissan Diesel engine 2.OL (Model MID), fulfilling EURO 5 emission standard, equipped with a cooled EGR, diesel oxidation catalyst (DOC) and regenerative wall-flow type DPF was used to obtain the soot. A stainless steel mesh was used to retain soot particles at the exhaust (figure 1). The experimental set-up used for analysis was a DRIFTS device consisting of a Fourier transform infrared spectrometer (Model Prestige-21, SHIMADZU), a diffuse reflectance spectroscopy accessory (model DRP-M-05, HARRICK SCIENTIFIC), a catalytic support for low temperature studies (Model CHCCHA-3, HARRICK SCIENTIFIC) and an automatic temperature controller (Model ATC-024-2, HARRICK SCIENTIFIC) (figure 2). KBr was selected as the non-absorbent compound for dilution of soot samples. Dilution samples of 1:1000, 1:500 and 1:200 were analyzed to check the signal sensitivity, and the 1:500 proportion was found to offer the best signal-to-noise ratio. Spectra were recorded in the spectral range 4000 to $600 \mathrm{~cm}^{-1}$ with a resolution of $4 \mathrm{~cm}^{-1}$. 


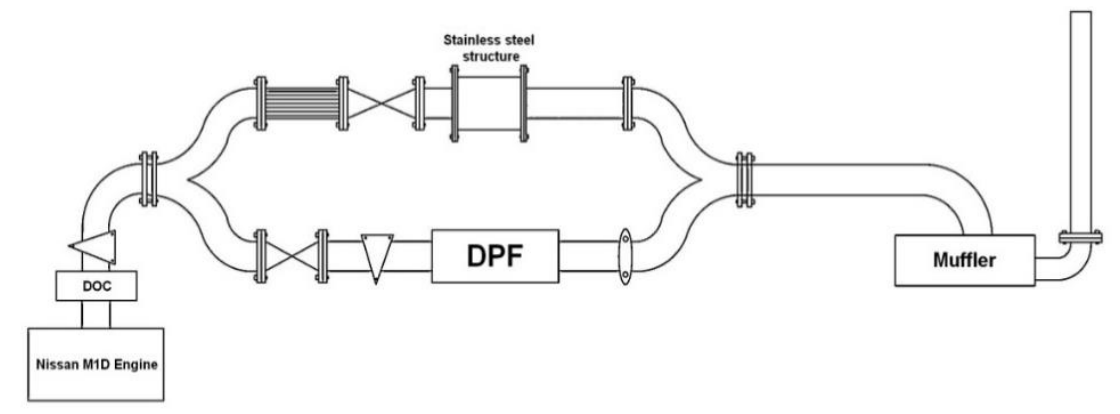

Figure 1. The exhaust configuration of the diesel engine used, which features a by-pass system for soot collection

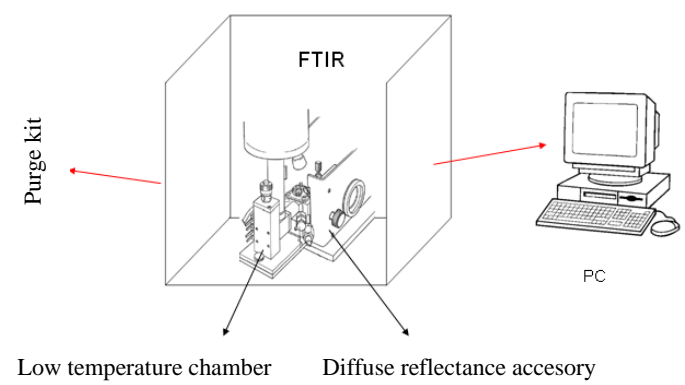

Figure 2. Experimental DRIFTS system

\section{Results and Discussion}

\subsection{Validation of the technique and experimental procedure}

The DRIFTS technique is normally used only for qualitative analysis of solid samples. As such, the repeatability of the infrared spectroscopy analysis and the sample preparation process were investigated with the aim of validating the technique for quantitative analysis. The experimental procedure comprises weighing fixed quantities of $\mathrm{KBr}$ and soot depending on the dilution level for the analysis, followed by mixing and grinding for thirty minutes.

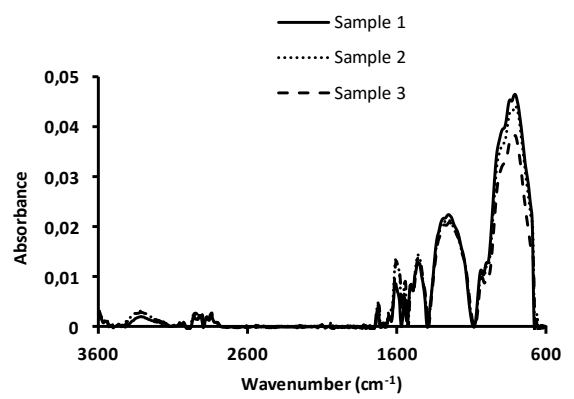

Figure 3. DRIFTS spectra of diesel soot at $298 \mathrm{~K}$ from 3600 to $600 \mathrm{~cm}^{-1}$ for three replicates of the same sample 
The mixing and grinding times were also optimized in initial experiments. A quantity of sample was then placed in the reaction chamber under vacuum and infrared spectra recorded in the range 4000 to $600 \mathrm{~cm}^{-1}$. The same sample was analyzed five times under the same conditions and the relative standard deviation in the spectral areas calculated was determined to assess the repeatability of the detection process.

Figure 3 shows the spectra for three replicates of the same sample analyzed in the repeatability study. As can be seen, the quantification of the spectral band between $1080 \mathrm{~cm}^{-1}$ and $675 \mathrm{~cm}^{-1}$ presents lower precision than the others. The values of the areas for the different infrared bands checked in the spectrum are shown in table 1 for all experiments performed. The relative standard deviations (RSD\%) were subsequently calculated, with the values obtained also being presented in the table. As can be seen, the repeatability of the IR analysis is high, with errors always lower than $20 \%$. Although there are currently no established guidelines for evaluation of the precision of soot measurements using the DRIFTS technique, relative standard deviations of less than $20 \%$ for IR analysis have been considered to be acceptable given the maximum value of $25 \%$ established for other types of analytical methods (USEPA, 2013).

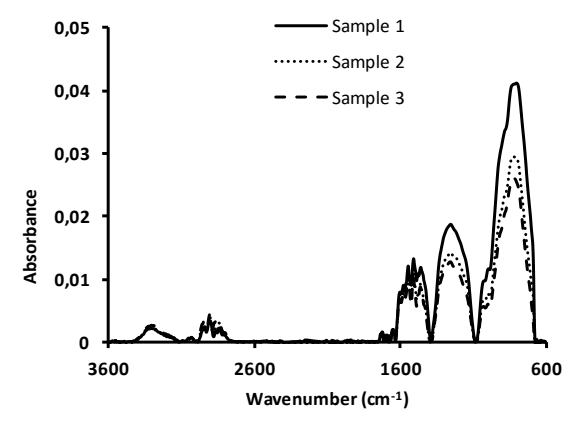

Figure 4. DRIFTS spectra of diesel soot at $298 \mathrm{~K}$ in the $3600-600 \mathrm{~cm}^{-1}$ range for the three samples used in the repeatability analysis

The repeatability study was completed by considering the procedure for preparing soot samples and its associated experimental errors. For this study, five different samples of diesel soot in $\mathrm{KBr}$, in a proportion of 1:500, were prepared and analyzed to determine the relative standard deviation in the computed integrated absorbances. Figure 4 shows the typical infrared spectra obtained upon analysing diesel soot in the range from 3600 to $600 \mathrm{~cm}^{-1}$ after correcting the baseline for three replicates. As can be seen in this figure, the spectral areas obtained are very similar for the different samples. Table 1 lists the RSD values for these experiments. When including sample preparation in the error evaluation, the relative standard deviation values obtained are higher due to errors resulting from the dilution process, although they remain acceptable for the analytical method. The infrared band between 2890 and $2775 \mathrm{~cm}^{-1}$ shows an RSD value higher than $25 \%$, possibly due to the low intensity of the signal detected in this case.

Given our experimental results, we can conclude that the DRIFTS technique allows us to obtain reproducible results when applied to diesel soot characterization and could therefore be an appropriate method for conducting comparative quantitative studies of different kinds of soot in light of the experimental errors in infrared band intensity obtained here.

\subsection{Analysis of diesel soot at room temperature}

As mentioned above, the DRIFTS technique has been used to chemically characterize samples of diesel soot obtained under fixed engine conditions. The total spectral range was has been divided in three zones to a better observation of the identified bands. Then qualitative analysis was carried out in the following ranges: $4000-2000 \mathrm{~cm}^{-1}, 2500-1000 \mathrm{~cm}^{-1}$ and $1500-600 \mathrm{~cm}^{-1}$. The spectra used for baseline correction are shown in figures 5, 6 and 7. Infrared bands of different intensity were found in each region, thus meaning that different functional groups are present on the surface of diesel soot, as has been demonstrated using other analytical techniques (Tapia et al., 2015). Table 2 lists the infrared bands identified for diesel soot 
in bibliographic references compared with data obtained in this work. Another column with the corresponding functional groups in accordance with standard infrared spectroscopic assignments and literature data has been included in the table for comparison. Polycyclic aromatic hydrocarbons are a group of compounds with low volatility that mainly appear adsorbed onto the surface of soot as a result of incomplete fuel combustion (Ballesteros et al., 2010).

Table 1. Relative standard deviation (RSD) values for the infrared absorption bands selected for DRIFTS analysis.

\begin{tabular}{|c|c|c|c|c|c|c|}
\hline \multirow[b]{2}{*}{ Wavenumber $\left(\mathrm{cm}^{-1}\right)$} & \multicolumn{3}{|c|}{$\begin{array}{l}\text { Repeatability of IR analysis } \\
(n=5)\end{array}$} & \multicolumn{3}{|c|}{ Repeatability including sample preparation $(n=5)$} \\
\hline & Experiment & Area & RSD (\%) & Experiment & Area & RSD (\%) \\
\hline \multirow{5}{*}{$3425-3125$} & 1 & - & \multirow{5}{*}{8.0} & 1 & 0.324 & \multirow{5}{*}{16.8} \\
\hline & 2 & 0.427 & & 2 & 0.367 & \\
\hline & 3 & 0.437 & & 3 & 0.378 & \\
\hline & 4 & 0.487 & & 4 & 0.458 & \\
\hline & 5 & 0.502 & & 5 & 0.487 & \\
\hline \multirow{5}{*}{$3000-2890$} & 1 & 0.134 & \multirow{5}{*}{18.4} & 1 & 0.14 & \multirow{5}{*}{12.4} \\
\hline & 2 & 0.178 & & 2 & 0.169 & \\
\hline & 3 & 0.181 & & 3 & 0.139 & \\
\hline & 4 & 0.209 & & 4 & 0.172 & \\
\hline & 5 & 0.222 & & 5 & 0.183 & \\
\hline \multirow{5}{*}{ 2890-2775 } & 1 & 0.136 & \multirow{5}{*}{13.9} & 1 & 0.061 & \multirow{5}{*}{26.6} \\
\hline & 2 & 0.132 & & 2 & 0.097 & \\
\hline & 3 & 0.106 & & 3 & 0.085 & \\
\hline & 4 & 0.156 & & 4 & 0.055 & \\
\hline & 5 & 0.146 & & 5 & - & \\
\hline \multirow{5}{*}{$1664-1525$} & 1 & - & \multirow{5}{*}{4.3} & 1 & 0.347 & \multirow{5}{*}{5.6} \\
\hline & 2 & 0.936 & & 2 & 0.369 & \\
\hline & 3 & 0.882 & & 3 & 0.388 & \\
\hline & 4 & 0.845 & & 4 & 0.372 & \\
\hline & 5 & 0.874 & & 5 & 0.337 & \\
\hline \multirow{5}{*}{$1525-1390$} & 1 & 1.02 & \multirow{5}{*}{6.5} & 1 & 0.568 & \multirow{5}{*}{15.4} \\
\hline & 2 & 1.162 & & 2 & 0.445 & \\
\hline & 3 & 1.118 & & 3 & 0.428 & \\
\hline & 4 & 1.179 & & 4 & 0.601 & \\
\hline & 5 & 1.211 & & 5 & 0.576 & \\
\hline \multirow{5}{*}{$1390-1080$} & 1 & 4.524 & \multirow{5}{*}{3.2} & 1 & 3.721 & \multirow{5}{*}{16.8} \\
\hline & 2 & 4.402 & & 2 & 2.793 & \\
\hline & 3 & 4.272 & & 3 & 2.427 & \\
\hline & 4 & 4.187 & & 4 & 3.496 & \\
\hline & 5 & 4.233 & & 5 & 3.277 & \\
\hline \multirow{5}{*}{$1080-675$} & 1 & 11.261 & \multirow{5}{*}{9.2} & 1 & 9.641 & \multirow{5}{*}{22.4} \\
\hline & 2 & 10.641 & & 2 & 6.606 & \\
\hline & 3 & 9.007 & & 3 & 5.38 & \\
\hline & 4 & 9.475 & & 4 & 8.793 & \\
\hline & 5 & 10.729 & & 5 & 8.482 & \\
\hline
\end{tabular}

Oxygenated functional groups are generated during the same process, and appear bonded to these aromatic compounds. Thus, the bands at $3381 \mathrm{~cm}^{-1}$ (figure 5) and $1244 \mathrm{~cm}^{-1}$ (figure 7) are associated with hydroxyl group and ether C-O-C group stretching, respectively (Zawadzki and Wisniewski, 2003; Cain et al., 2010). Similarly, the carbonyl functional group is associated with the band at $1718 \mathrm{~cm}^{-1}$ (Santamaría et al., 2010). The value of the wavenumber for this $C=0$ group varies depending on the chemical nature of the molecule, with molecules such as quinones, lactones and carboxylic acids exhibiting carbonyl bands at wavenumbers of 1604, 1701, 1685 and $1670 \mathrm{~cm}^{-1}$ (Coury and Dillner, 2008) signals observed in the spectrum of figure 6 . Bands corresponding to the $\mathrm{C}-\mathrm{H}$ stretching vibration in aromatic structures are found 
at 3053 and $3034 \mathrm{~cm}^{-1}$ (figure 5), whereas bands at 2947, 2926, 2902, $28642843 \mathrm{~cm}^{-1}$ are assigned to the asymmetric and symmetric $\mathrm{C}-\mathrm{H}$ stretching vibrations of aliphatic $\mathrm{CH}_{3}$ and $\mathrm{CH}_{2}$ groups (Santamaría et al., 2006).

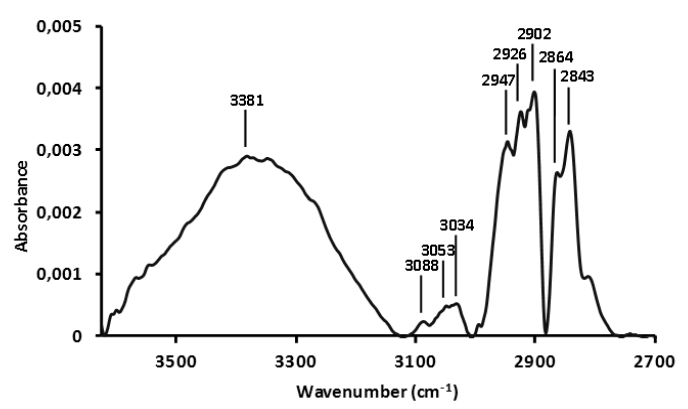

Figure 5. DRIFTS spectra of diesel soot at $298 \mathrm{~K}$ from 3625 to $2700 \mathrm{~cm}^{-1}$ range

Table 2. Assignment of infrared bands to functional groups on diesel soot at $298 \mathrm{~K}$. Second column shows typical wavenumber values found in soot bibliographic references, third column shows values for standard infrared spectroscopic assignments for functional groups and fourth column values found in this work.

\begin{tabular}{|c|c|c|c|}
\hline Assignment & $\begin{array}{l}\text { Wavenumber }{ }^{a, b, c} \\
\left(\mathrm{~cm}^{-1}\right)\end{array}$ & $\begin{array}{l}\text { Wavenumber } \\
\left(\mathrm{cm}^{-1}\right)\end{array}$ & Wavenumber $\left(\mathrm{cm}^{-1}\right)$ \\
\hline $\mathrm{O}-\mathrm{H}$ & $3620-2500$ & $3650-3200$ & 3381 \\
\hline Aromatic $\mathrm{C}-\mathrm{H}$ stretch & 3050,3030 & $3080-3030$ & 3053,3034 \\
\hline $\begin{array}{l}\text { Asymmetric and symmetric } \mathrm{C}-\mathrm{H} \text { stretching of } \mathrm{CH}_{3} \\
\text { and } \mathrm{CH}_{2} \text { aliphatic groups, respectively }\end{array}$ & $\begin{array}{l}2975,2925 \\
2850\end{array}$ & $3000-2840$ & $\begin{array}{c}2947,2926,2902 \\
2864,2843\end{array}$ \\
\hline Carbonyl $\mathrm{C}=\mathrm{O}$ stretching & 1720 & $1765-1645$ & 1718 \\
\hline Quinones & $1680-1550$ & 1675 & 1604 \\
\hline Lactones & $1790-1675$ & $1790-1650$ & $1701,1685,1670$ \\
\hline Carboxylic acids & $1760-1665$ & $1800-1650$ & \\
\hline $\begin{array}{c}\text { Asymmetric } \mathrm{CH}_{3} \text { and scissor } \mathrm{CH}_{2} \text { deformations and } \\
\text { symmetric } \mathrm{CH}_{3} \text { deformation and cyclic } \mathrm{CH}_{2}\end{array}$ & $1450-1380$ & $\begin{array}{l}1470-1430 \\
1395-1365 \\
\end{array}$ & 1454 \\
\hline Ether $\mathrm{C}-\mathrm{O}-\mathrm{C}$ stretching & 1260 & $1310-1000$ & 1244 \\
\hline $\begin{array}{l}\text { C-H bending out-of-plane of condensed aromatic } \\
\text { systems }\end{array}$ & $890,840,750$ & $900-650$ & 786 \\
\hline
\end{tabular}

${ }^{a}$ Santamaría et al., 2006, ${ }^{b}$ Cain et al., 2010, ' Figueiredo et al., 1999, ${ }^{d}$ Pretsch et al., 2009.

Bands at $1454 \mathrm{~cm}^{-1}$ (figure 6) correspond to asymmetric and symmetric $\mathrm{CH}_{3}$ and scissor $\mathrm{CH}_{2}$ deformations, thus meaning that aliphatic structures are also present on the soot's surface. The band at 786 (figure 7) can be assigned to the presence of $\mathrm{C}-\mathrm{H}$ stretching out-of-plane vibrations of substituted aromatic and alkene systems (Daly and Horn, 2009).

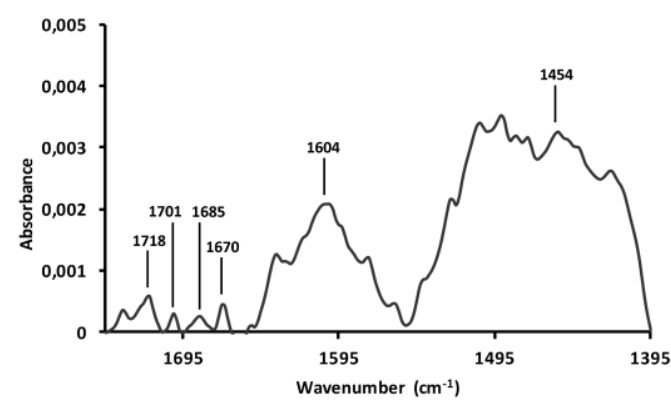

Figure 6. DRIFTS spectra of Diesel soot at $298 \mathrm{~K}$ from 1745 to $1395 \mathrm{~cm}^{-1}$ range 


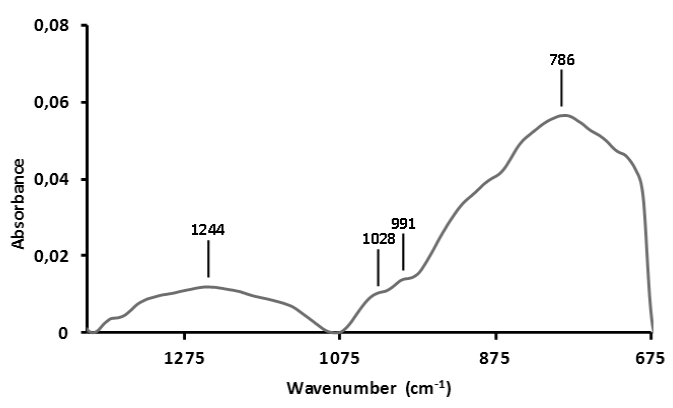

Figure 7. DRIFTS spectra of diesel soot at $298 \mathrm{~K}$ in the range $1400-675 \mathrm{~cm}^{-1}$ range

\subsection{Analysis of diesel soot at different temperatures}

Oxygenated functional groups on the surface of soot are desorbed at different temperatures depending on their thermal stability. Thus, Muckenhuber and Grothe (2006) have used temperature programmed desorption mass spectroscopy (TPD-MS) to distinguish and assign functional groups in commercial soot samples on the basis of their thermal stability (figure 8).

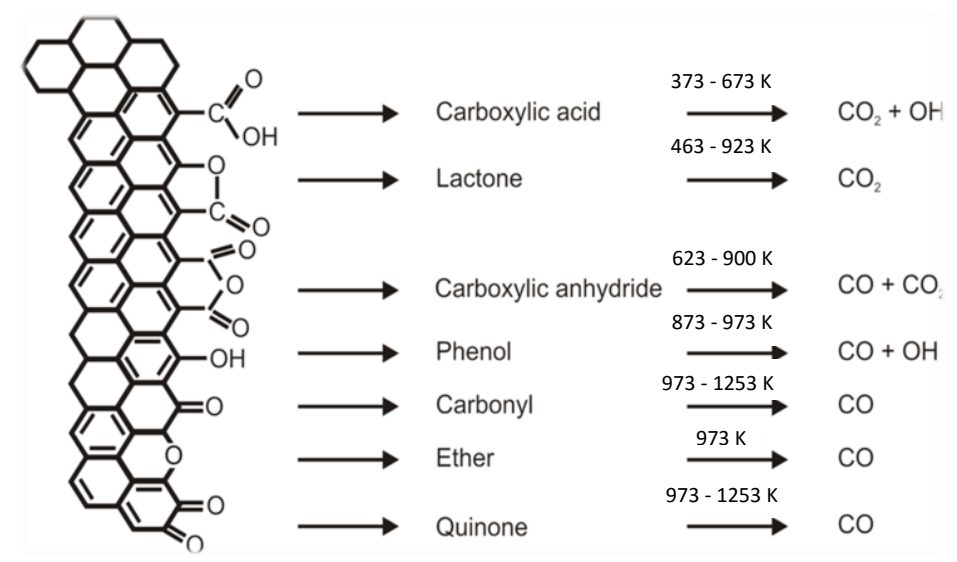

Figure 8. Temperature range for the thermal decomposition of functional groups on soot surfaces (Muckenhuber and Grothe, 2006)

Similarly, Setiabudi et al. (2004) have identified the role of $\mathrm{O}_{2}$ and $\mathrm{NO}_{2}$ in the reaction with soot at elevated temperatures using the DRIFTS technique. In our study, the sample was heated from 298 to $859 \mathrm{~K}$ using an automatic temperature controller and the evolution of the infrared bands was analyzed in order to identify signals coming from oxygenated functional groups on soot. Figure 9 shows the evolution of the infrared bands with increasing temperature in a typical experiment. As can be seen, the intensity of the infrared bands decreases with increasing temperature, with the exception of the bands at 1718, 1701 and $1244 \mathrm{~cm}^{-1}$, which correspond to carbonyl, lactone and ether functional groups, the intensity of which does not change on heating from 298 to $573 \mathrm{~K}$. This suggests that carbonyl, lactone and ether groups are thermally more stable than the other groups and are not desorbed until higher temperatures ( $859 \mathrm{~K})$ are reached.

\section{Conclusions}

Diffuse Reflectance Infrared Fourier Transform Spectroscopy has been used to characterize the functional groups present on the surface of diesel soot. A validation study of the analytical method showed acceptable repeatability values considering both DRIFTS spectral acquisition and sample preparation. The IR spectra revealed the presence of aromatic polycyclic hydrocarbons containing oxygenated functional 
groups, such as phenols, quinones, lactones, carboxylic acids and ethers, on diesel soot as a result of the incomplete combustion of diesel fuel. Carbonyl, lactone and ether groups are desorbed from the soot surface at higher temperatures than other groups, thus meaning that they are thermally more stable. The presence of these compounds adsorbed on diesel soot is important from an environmental point of view as they could affect the heterogeneous processes that take place in the atmosphere.

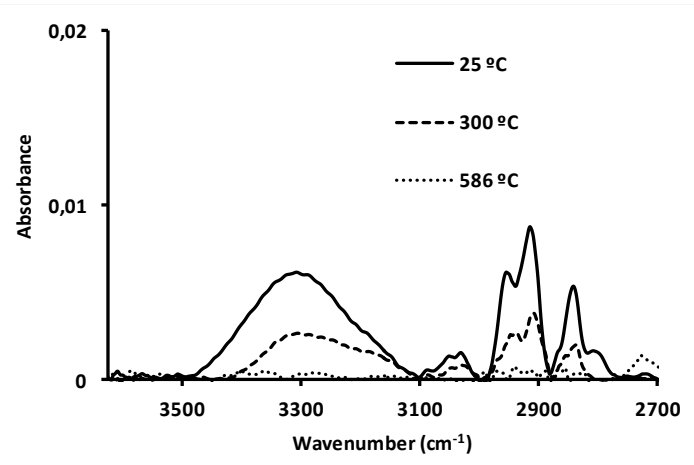

(a)

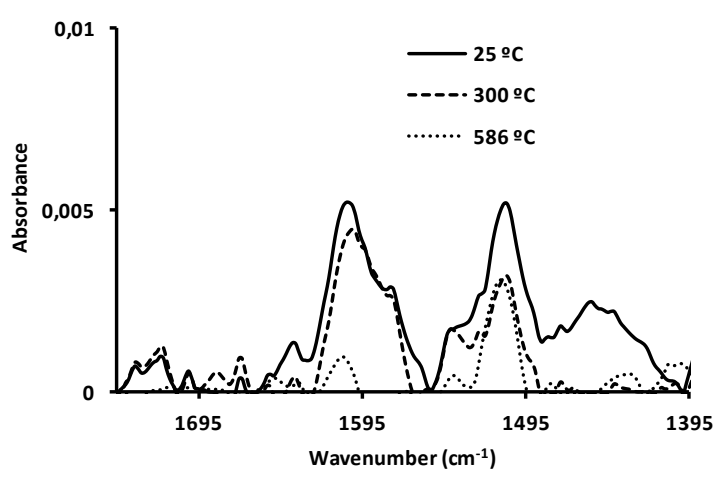

(b)

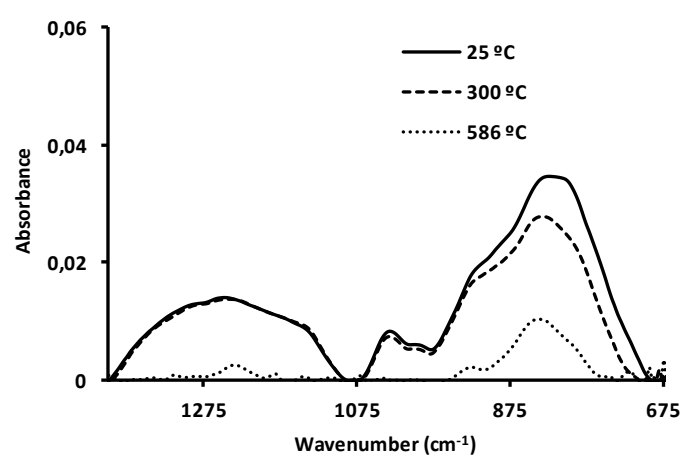

(c)

Figure 9. DRIFTS spectra recorded for Diesel soot in several wavenumber ranges after heat treatment: (a) $3625 \mathrm{~cm}^{-1}-2700 \mathrm{~cm}^{-1}$, (b) $1745 \mathrm{~cm}^{-1}-1395 \mathrm{~cm}^{-1}$, (c) $1400 \mathrm{~cm}^{-1}-675 \mathrm{~cm}^{-1}$

\section{Acknowledgments}

This work was supported by project ENE2007-67529-CO2-02 granted by the Ministerio de Educación y Ciencia. 


\section{References}

Ballesteros R., Hernández J.J. and Lyons L.L. (2010), An experimental study of the influence of biofuel origin on particle-associated PAH emissions, Atmospheric Environment, 44(7), 930-938.

Beatrice C., Di lorio S., Guido C. and Napolitano P. (2012), Detailed characterization of particulate emissions of an automotive catalyzed DPF using actual regeneration strategies, Experimental Thermal and Fluid Science, 39, 4553.

Braun A., Shah N., Huggins F.E., Kelly K.E., Sarofim A., Jacobsen C., Wirick S., Francis H., Ilavsky J., Thomas G.E. and Huffman G.P. (2005), X-ray scattering and spectroscopy studies on diesel soot from oxygenated fuel under various engine load conditions, Carbon, 43, 2588-2599.

Cain J.P., Gassman P.L., Wang H. and Laskin A. (2010), Micro-FTIR study of soot chemical composition-evidence of aliphatic hydrocarbons on nascent soot surfaces, Physical Chemistry Chemical Physics, 12, 5206-5218.

Coury C. and Dillner A.M. (2008), A method to quantify organic functional groups and inorganic compounds in ambient aerosols using attenuated total reflectance FTIR spectroscopy and multivariate chemometric techniques, Atmospheric Environment, 42, 5923-5932.

Daly H.M. and Horn A.B. (2009), Heterogeneous chemistry of toluene, kerosene and diesel soots, Physical Chemistry Chemical Physics, 11, 1069-1076.

Figueiredo J.L., Pereira M.F.R., Freitas M.M.A. and Órfao J.J.M. (1999), Modification of the surface chemistry of activated carbons, Carbon, 37, 1379-1389.

Geller M.D., Ntziachistos L., Mamakos A., Samaras Z., Schmitz D.A., Froines J.R. and Sioutas C. (2006), Physicochemical and redox characteristics of particulate matter (PM) emitted from gasolina and diesel passenger cars, Atmospheric Environment, 40, 6988-7004.

Górski K., Sen A.K., Lotko W. and Swat M. (2013), Effects of ethyl-tert-butyl ether (ETBE) addition on the physicochemical properties of diesel oil and particulate matter and smoke emissions from diesel engines, Fuel, 103, 1138-1143.

Guo X., Nakayama T., Yamada H., Inomata S., Tonokura K. and Matsumi Y. (2014), Measurement of the light absorbing properties of diesel exhaust particles using a three-wavelenghth photoacoustic spectrometer, Atmospheric Environment, 94, 428-437.

Jäger C., Huisken F., Mutschke H., Henning Th., Poppitz W. and Voicu I. (2007), Identification and spectral properties of PAHs in carbonaceous material produced by laser pyrolysis, Carbon, 45, 2981-2994.

Lapuerta M., Rodríguez-Fernández J. and Oliva F. (2012), Effect of soot accumulation in a diesel particle filter on the combustion process and gaseous emissions, Energy, 47(1), 543-552.

Lee S., Jang M. and Kamens R.M. (2004), SOA formation from the photooxidation of $\alpha$-pinene in the presence of freshly emitted diesel soot exhaust, Atmospheric Environment, 38, 2597-2605.

Liati A., Eggenschwiler P.D., Schreiber D., Zelenay V. and Ammann M. (2013), Variations in diesel soot reactivity along the exhaust after-treatment syste, based on the morphology and nanostructure of primary soot particles, Combustion and Flame, 160, 671-681.

Liu Y., Liu C., Ma J., Ma Q. and He H. (2010), Structural and hygroscopic changes of soot during heterogeneous reaction with $\mathrm{O}_{3}$, Physical Chemistry Chemical Physics, 12, 10896-10903.

Muckenhuber H. and Grothe $\mathrm{H}$. (2006), The heterogeneous reaction between soot and $\mathrm{NO}_{2}$ at elevated temperature, Carbon, 44, 546-559.

Muckenhuber H. and Grothe $\mathrm{H}$. (2007), A DRIFTS study of the heterogeneous reaction of $\mathrm{NO}_{2}$ with carbonaceous materials at elevated temperature, Carbon. 45, 321-329.

Pino T., Dartois E., Cao A.T., Carpentier Y., Chamaillé Th., Vasquez R., Jones A.P., d'Hendecourt L. and Bréchignac Ph. (2008), The $6.2 \mu \mathrm{m}$ band position in laboratory and astrophysical spectra: a tracer of the aliphatic to aromatic evolution of interstellar carbonaceous dust, Astronomy and Astrophysics, 490, 665-672.

Pretsch E., Bühlmann P. and Badertscher M. (2009), Structure Determination of Organic Compounds. Tables of spectral data. Springer Verlag, Berlin-Heidelberg-Nueva York.

Russo C., Stanzione F., Tregossi A., Alfè M. and Ciajolo A. (2012), The effect of temeperature on the condensed phases formed in fuel-rich premixed benzene flames, Combustion and Flame, 159, 2233-2242. 
Sadezky A., Muckenhuber H., Grothe H., Niessner R. and Pöschl U. (2005), Raman microspectrocopy of soot and related carbonaceous materials: spectral analysis and structural information, Carbon, 43, 1731-1742.

Salamanca M., Mondragón F., Agudelo J.R. and Santamaría A. (2012), Influence of palm oil biodiesel on the chemical and morphological characteristics of particulate matter emitted by a diesel engine, Atmospheric Environment, 62, 220-227.

Santamaría A., Mondragón F., Molina A., Marsh N.D., Eddings E.G. and Sarofim A.F. (2006), FT-IR and ${ }^{1} \mathrm{H}$ NMR characterization of the products of an ethylene inverse diffusion flame, Combustion and Flame, 146, 52-62.

Santamaría A., Yang N., Eddings E. and Mondragon F. (2010), Chemical and morphological characterization of soot and soot precursors generated in an inverse diffusion flame with aromatic and aliphatic fuels, Combustion and Flame, 157, 33-42.

Schnaiter M., Horvath H., Möhler O., Naumann K.H., Saathoff H. and Schöck O.W. (2003), UV-VIS-NIR spectral optical properties of soot and soot-containing aerosols, Journal of Aerosol Science, 34, 1421-1444.

Setiabudi A., Makkee M. and Moulijn J.A. (2004), The role of $\mathrm{NO}_{2}$ and $\mathrm{O}_{2}$ in the accelerated combustion of soot in diesel exhaust gases, Applied Catalysis B: Environmental, 50, 185-194.

Steiner S., Czerwinski J., Comte P., Popovicheva O., Kireeva E., Müller L., Heeb N., Mayer A., Fink A. and RothenRutishauser B. (2013), Comparison of the toxicity of Diesel exhaust produced by bio- and fossil Diesel combustion in human lung cells in vitro, Atmospheric Environment, 81, 380-388.

Tapia A., Salgado M.S., Martín M.P., Sánchez-Valdepeñas J., Rossi M.J. and Cabañas B. (2015), The use of heterogeneous chemistry for the characterization of functional groups at the gas/particle interface of soot from a diesel engine at a particular running condition, Environmental Science and Pollution Research, 22, 4863-4872.

Tighe C.J., Twigg M.V., Hayhurst A.N. and Dennis J.S. (2012), The kinetics of oxidation of diesel soot by $\mathrm{NO}_{2}$, Combustion and Flame, 159, 77-90.

USEPA. (2013). Quality Assurance Handbook for Air Pollution Measurement Systems. Volume II.

Vieira de Souza C. and Machado Corrêa S. (2015), Polycyclic aromatic hydrocarbon emissions in diesel exhaust using gas chromatography-mass spectrometry with programmed temperature vaporization and large volume injection, Atmospheric Environment, 103, 222-230.

Wentzel M., Gorzawski H., Naumann K.H., Saatho H. and Weinbruch S. (2003), Transmission Electron Microscopical and Aerosol Dynamical Characterization of Soot Aerosols, Journal of Aerosol Science, 34,1347-1370.

Yehliu K., Vander Wal R.L., Armas O. and Boehman A. (2012), Impact of fuel formulation on the nanostructure and reactivity of diesel soot, Combustion and Flame, 159, 3597-3606.

Zawadzki J. and Wisniewski M. (2003), In situ characterization of interaction of ammonia with carbon surface in oxygen atmosphere, Carbon, 41, 2257-2267.

Zouaoui N., Labaki M. and Jeguirim M. (2014), Diesel soot oxidation by nitrogen dioxide, oxygen and water under engine exhaust conditions: Kinetics data related to the reaction mechanism, Comptes Rendus Chimie, 17, 672680. 